\title{
OBSERVATIONS AND EXPERIMENTS ON THE PATHOLOGY OF GRAVES'S DISEASE.
}

\author{
By Walter Edmunds, M.A., F.R.C.S.
}

(Plates XXIV. to XXXIV.)

Microscopic examination of the enlarged thyroid constituting an ordinary goitre shows various changes; there are found-

1. A tissue differing from the normal thyroid only in being somewhat coarser.

2. Cysts, some containing colloid material, and some a papillomatous ingrowth.

3. Nævoid or erectile tissue : this explains the expansile pulsation and thrill felt in some goitres, and also the hæmorrhage which during operations sometimes occurs from the thyroid tissue itself : this as a rule does not bleed, any hæmorrhage which arises coming from the capsule, which is highly vascular (Plate XXV. Fig. 9).

4. Myxomatous changes of the interacinous tissue; this tissue then stains of a pale colour, and thus contrasts with the colloid contents of the vesicles. Sometimes the vesicles contain in their centre normal dark-staining colloid, and external to this, next the lining cells, a layer which stains much more palely (Plate XXV. Fig. 6 and Plate XXIV. Fig. 34).

5. Tissue of an embryonic type, consisting mainly of secreting cells, and not containing either vesicles or colloid (Plate XXIV. Fig. 5 and Plate XXV. Fig. 6).

The goitre of Graves's disease does not differ greatly from others, but a remarkable hypertrophy of the blood vessels is sometimes found, and the presence of the "embryonic" (small-celled) tissue is, as Greenfield points out, fairly constant (Plate XXXII. Fig. 30 and Plate XXIV. Fig. 5).

This tissue resembles that of the parathyroid glands.

These glands are recognised most easily in rabbits, for in them they are situate quite apart from the thyroid proper; they are of a bright red colour, and lie one on each side of the trachea below and at a considerable distance from the thyroid. They consist mainly of secreting cells arranged more or less in columns; there are no vesicles 
and no colloid; these glands were first described by Sandström in 1880 (Plate XXVIII. Fig. 20 and Plate XXX. Fig. 26).

In rabbits it has long been noticed that excision of the thyroid gland is not followed by the same fatal result that attends the operation almost (though not quite) invariably in dogs and cats; but Gley has recently shown that in rabbits, if, as well as the thyroid, the parathyroid glands are removed, the animal, as a rule, dies. These experiments of Gley's have been repeated by myself, and it was found (1) that if both the thyroid and the parathyroid glands are removed the animals die; out of a batch of 7 rabbits, on whom this operation was performed, 5 died within 8 days, the other 2 surviving for months. (2) That when the thyroid gland only is excised, the parathyroid glands being left, many of the animals also die; in a batch of 7 operated on, 5 died within 42 days, and 2 survived for months; in another set of 17 operations, 2 were killed while in good health (at the fifty-second and the fiftyninth day), and the remaining 15 all died within 97 days; in 4 of them there was noticed a condition resembling myxodema in man; the general health failed, the hair fell out, and there was a remarkable cdema of the lower part of the face. (3) If the parathyroids are alone extirpated, the animals, as a rule, live, and do not undergo any obvious change, at least not for a long time. In a batch of 7 , one died at the thirty-fifth day, a second the eighty-second day, and a third the one hundred and fifty-sixth day; the other 4 survived; 2 of these now, after 6 months, are weak and emaciated.

The appearance of some of these parathyroidless rabbits gave rise to the suspicion that the operation caused exophthalmos, and a fresh series of experiments (with controls) was made to test this point; the result seemed clear, the operation did not cause exophthalmos,indeed, after the lapse of 6 months, the eyes in 2 or 3 of these operated rabbits looked sunken, as if they were suffering from the opposite condition of exophthalmos. It is therefore proposed to make another series of experiments to decide as to this.

The parathyroids after extirpation of the thyroids do not undergo any marked changes, but they may hypertrophy somewhat; under the microscope, too, there is no pronounced alteration of minute structure; they do not develop into normal thyroids; no vesicles, and no colloid form (Plate XXVIII. Fig. 19).

In dogs, also, there are parathyroids, but in them these small glands lie half-embedded in the substance of the thyroid itself; consequently, in excision of the thyroid lobes; the parathyroids have been removed as well (Plate XXVIII. Fig. 16). Gley found that if the parathyroids are. separated and left, the animal will live, notwithstanding the removal of the rest of the thyroid lobes. The present writer's experiments ( 6 in number) show that if the whole of one lobe of the thyroid, including its parathyroid, and also the 
greater part (two-thirds or more) of the other lobe be removed, the animal will live or die, according as the parathyroid is or is not left.

The parathyroid, and also the portion of thyroid that is left in these experiments, hypertrophy considerably.

The hypertrophied parathyroid consists only of new columns of secreting cells, and has not developed into thyroid proper; no vesicles nor colloid formed in the two specimens I examined.

The hypertrophied portion of thyroid proper contains a considerable growth of new tubules lined with a single layer of secreting cells; there also appears to be less colloid in the vesicles, as if it had been absorbed; in one case many vesicles were empty (Plate XXVIII. Fig. 18 and Plate XXIX. Fig. 21). Further, the cells lining the vesicles are greatly hypertrophied, as described by Hürthle; they have become much larger than natural, and generally both in normal and enlarged thyroids the larger cells seem the more active cells, and this throws some light on the "vacuoles," which are found in both normal and diseased thyroids in the periphery of the colloid in the vesicles. The so-called "vacuoles" are to be seen in alcoholhardened specimens; and, from the fact that they are not present after osmium fixing, it has been supposed they are due to shrinking from the action of the alcohol, but they seem too regularly disposed for this, and their absence from the vicinity of flat (non-acting) cells points to their probably consisting of tiny portions of recent secretion, which has not yet become mixed with the rest of the colloid.

Later experiments show that a dog can live with only one parathyroid, that is to say, after the other parathyroid and the whole of the thyroid proper have been removed. If both parathyroids are removed, the dog appears to require at least three-quarters of one of the two thyroid lobes.

Parathyroids also occur in the sheep, monkey, and in the human subject. Creswell Baber has found them in the seal (Plate XXV. Figs. 7 and 8, Plate XXVI. Fig, 1, and Plate XXIX. Figs. 22 and 23).

The parathyroid gland is, it is clear, of considerable importance; it is not quite so important as the thyroid gland, but, bulk for bulk, it probably is more so, as it is considerably the smaller. In a rabbit weighing 1800 grms. the thyroid weighed 220 mgrms., and the parathyroids together 19 mgrms., or about one-twelfth of the thyroid.

Although the tissue of the parathyroid gland does not at all resemble that of the thyroid in its adult form, there can be little doubt that they are closely connected, not only on account of one being able, to a great extent, to replace the other physiologically, but also because-(1) the parathyroid resembles the embryonic form of the thyroid; (2) the two tissues are occasionally found side by side in the parathyroid of the dog; and (3) because they are closely connected anatomically; in the monkey the parathyroid is embedded in the substance of the thyroid. 
Now, it has been supposed that the symptoms of Graves's disease (other than the goitre) are due to the action of the internal secretion from the enlarged thyroid; there, however, exists little, if any, evidence that thyroid secretion can produce exophthalmos. The eating of the thyroid of sheep, or the receiving of the subcutaneous injection of the extract, has produced unpleasant symptoms in healthy persons; in the subjects of myxcedema an excessive dose has produced grave and, it is stated, even fatal symptoms, but it has seldom, if ever, appeared that the eye symptoms of Graves's disease were among these effects.

In animals, thyroid feeding produced, in my hands, no very obvious results, certainly no exophthalmos. To a healthy dog were given, in 1 day, the thyroids of 16 sheep, without any apparent result, and to another dog were given sheep's thyroids, 2 per diem, for some days without effect. Also monkeys were treated daily with large doses of the extract subcutaneously, without the production of obvious symptoms, except that in one case, about the time of stopping the treatment, suddenly an area of baldness appeared on each temple, extending downwards to the shoulder; this hair gradually grew again, but an attempt to reproduce the result in the same monkey by the reapplication of the supposed cause, i.e. the administration of thyroid extract in large doses and then suddenly stopping it, failed.

If it be argued that the thyroid of Graves's disease is not merely an enlarged one, but is also altered in structure, and that therefore the secretion is also probably altered, it must be answered that that may well be, but that no evidence has yet been brought forward that this altered secretion can produce exophthalmos. It would certainly be desirable, as has been suggested, to try, when opportunity offers, the physiological effect of the secretion found in the enlarged thyroid in Graves's disease.

The apparent contrast between the symptoms of Graves's disease and myxœdema, coupled with the brilliant success which has attended the treatment of the latter, and also of cretinism ${ }^{1}$ by thyroid taking, certainly helps the secretion theory. But there are one or two considerations that go against it.

1. The contrast between Graves's disease and myxœdema only holds good with chronic myxodema; in the acute myxœdema as seen in dogs, and sometimes in monkeys, there are tremors, with attacks of dyspnœa resembling those of Graves's disease.

2. Two cases have been described (by Sollier) of the coexistence in the same patient at the same time of Graves's disease and myxœdema. Zum Busch has recently recorded a case of Graves's disease in which myxœdema supervened and partially replaced the symptoms of Graves's disease; the myxœdema was cured by thyroid treatment, but exophthalmos and Graves's sign remained.

1 Plate XXVIII. Fig. 17. 
3. Thyroid feeding does not as a rule make cases of Graves's disease worse. Dr. Mackenzie tells me he tried the treatment in a series of cases without marked result in either direction. Auld has, however, recorded a case in which injurious results followed, and appeared to have been caused by the treatment. I have heard, too, of one or two other cases in which the same effect has been observed; but this effect is, I submit, the exception, and not the rule.

4. The difficulty of saving by thyroid treatment animals deprived of their thyroids tells against the secretion theory. Twenty dogs, whose thyroids were excised, were treated by thyroid feeding, or by the administration of the extract of thyroid: the details of the treatment were varied, and also of the operation; the thyroid in some cases was removed in stages. The total result was that only 2 out of the 20 were saved: this is, however, more than could have been expected without treatment, judging from the experience both of myself and others. The survivals are stated to be less than 5 per cent.; moreover, the dogs lived a few days longer than they would have done without the treatment, and the symptoms were much modified, for the acute attacks of dyspnœa and rapid breathing were absent, the animals dying of emaciation and asthenia.

It is worthy of note that in neither of the two cases saved were there any symptoms, and that after the lapse of a few weeks the treatment was entirely stopped, without ill effects. In one of the cases a post-mortem examination was made, and no trace of thyroid tissue was discoverable. The pituitary body was larger than that of another dog of about the same size, but this I am disposed to regard as merely accidental.

In monkeys, 8 were treated with thyroid extract administered subcutaneously in all cases but one; they all died in from 12 to 128 days, the average time of survival being 44 days. The symptoms from which they suffered were those of myxcedema in monkeys, as described by Horsley; they lost weight, became less lively, respiration became slower, hair fell out in places, cedema appeared in the face, and the pupil was somewhat dilated; tremors occurred, and sometimes convulsive attacks, with rigidity of limbs.

Stanley Kent's results in cats are in accord: of 5 submitted to thyroidectomy and treated he saved only 1 ; and of 4 in which the thyroid, and also one or both testes, were removed, and the treatment followed, 2 died, 1 was killed while ill, and only 1 survived.

Another argument for the secretion theory is found in the cure or amelioration of Graves's disease, wbich, now, many times has followed the removal of the whole or part of the enlarged thyroid. One of the latest to review these cases is Dr. Oppenheimer, of Baltimore, who finds a total of 68 on record: of these, 18 are said to have completely recovered; 26 were more or less improved; in 9 
there was no change either way; in 5 there was immediate death; and in 4 death followed the operation within 24 hours.

One case of improvement, amounting practically to cure, has come under my own observation. The case was seen almost from the commencement of the symptoms, and treated, but without success; it gradually became worse, the patient at last being very ill, with the usual symptoms, including the paroxysmal attacks of palpitation and rapid breathing. The only course that seemed left was to operate on the goitre, but before undertaking this step a consultation was held with Dr. Hector Mackenzie. He agreed in the advisability of the operation, and also in considering the spasmodic attacks to be due to the effects of the disease itself, and not to the mechanical pressure of the goitre on the trachea. The attacks resembled those which occur in thyroidless dogs. A considerable portion (but not all) of the goitre was removed; the patient was much benefited, and the symptoms gradually passed off, so that the patient was practically well, though the pulse, if counted, was found too fast, a little exophthalmos might still have been detected on critical examination (at no time was it a prominent symptom), and occasionally an attack of dyspnoea occurred.

It is argued that the improvement must be due to the diminution of the thyroid secretion, following the removal of a portion of the thyroid, and that therefore the symptoms are due to that cause; but it must be remembered that for these cures to take place it is not apparently necessary that the whole or nearly the whole of the goitre should be removed; in some cases only one lobe has been excised, the remainder atrophying in time. This, too, is only what occurs in operations on ordinary goitre. In a case in which about half of a considerable goitre (which was compressing the trachea) was removed, the remaining portion gradually atrophied, so that in about a year the thyroid could not be detected, and the patient was well. These latter cases can only be explained by the breaking of some vicious circle, and the same explanation may apply in the cases of Graves's disease. Moreover the improvement, as we have seen, does not always follow: Dr. Mackenzie informs me of a case under his care of 10 years' standing, in which a considerable portion of the goitre was excised, in the hope of benefiting the exophthalmos, which was extreme; the patient was not improved, certainly not in the exophthalmos.

The fact that the eye symptoms of Graves's disease can be produced by a chemical poison (cocain) may be held to support the view that a poison secreted by the thyroid might do the same.

The effects of cocain in this connection were first pointed out by Koller, and have since been carefully studied by Jessop; the latter found that by dropping cocain into the eye there was produced-(1) proptosis, (2) absence of winking, (3) Graefe's sign, (4) local anæsthesia, (5) dilatation of pupil, (6) widening of the palpebral 
fissure, (7) paralysis of accommodation, (8) diminution of ocular tension.

In a case of complete facial paralysis cocain still caused widening of the palpebral fissure, and he argues that the cocain must act on the unstriped muscular fibres (which are supplied by the sympathetic). His experiments also show that stimulation of the sympathetic in the neck could further dilate a pupil already as fully dilated as atropine could make it; and that cocain could also dilate a pupil fully dilated with atropine. In a case of Graves's disease he found that cocain administered cautiously produced increased proptosis, further dilatation of palpebral fissure, and halting in the descent of the upper eyelid.

Jessop also found that in the rabbit, if the cervical sympathetic be divided, after a few days cocain will not produce dilatation of pupil, nor proptosis, nor widening of the palpebral fissure.

The effects of cocain injected subcutaneonsly in monkeys, both with and without division of the cervical sympathetic, have been tried by myself. The results in monkeys of division and stimulation of the cervical sympathetic are described by Sherrington in the Journal of Physiology, and represented in the figure here reproduced.

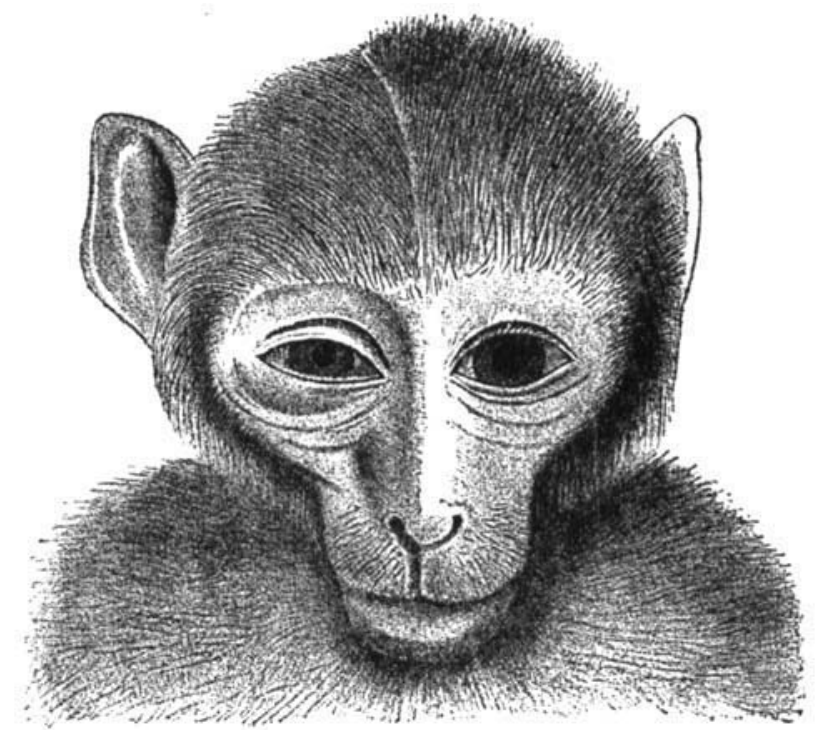

Fra. 1. - Shows effects on division of right cervical sympathetic nerve. Sketch ad nat.

Division of cervical sympathetic causes-(1) recession of eyeball, (2) contraction of pupil, (3) narrowing of palpebral fissure, (4) œdema and flushing of skin round eye, (5) swelling of caruncle, (6) projection of pinna from side of head, (7) puckering of skin of muzzle, (8) flattening of certain hairs on forehead, which cannot then 
be elevated by the emotions which will raise the corresponding hairs on the opposite (normal) side of the head.

Stimulation of the cervical sympathetic, on the other hand, produces-(1) proptosis of the eyeball, (2) dilatation (well marked) of pupil, (3) widening of palpebral fissure, (6) lying back of pinna, (8) erection of certain hairs on forehead.

The solution of cocain used was the hydrochlorate, and it was found that 2 grs. of the salt $(=0.13 \mathrm{grm}$.) was fatal to a monkey. Immediately after the injection he jumped about in an excited manner; then his movements became less precise, and soon he had to hold on to the side of his cage to retain the erect attitude; then his hold relaxed, and he collapsed on the Hoor of the cage, and had a succession of attacks of clonic spasms, during which the arms were extended and the hands clenched, the head partly thrown back, and the upper eyelids retracted. These attacks lasted about 4 seconds, with intervals of 15 seconds. Gradually the respiration became feebler, and notwithstanding artificial respiration he died in 20 minutes or half an hour from the time of injection. After death it was noticed that the eyelids were unusually widely open, the upper eyelid being retracted, and that the eyes were prominent (as shown by comparison with a normal monkey). Half an hour after death the cornea was still clear and convex instead of hazy and flaccid, as it usually becomes.

The cocain experiments were made on 12 monkeys altogether. The drug was injected subcutaneously in half-grain doses $(=0.032$ grm.) once a day, but it being found that this when continued produced death, the dose in the later experiments was reduced to a third or a quarter of a grain. Five of the monkeys died certainly from the effects of the injections, and 3 others probably from the same cause; 2 of the 5 died in convulsions.

The effect of the injections caused the animals to seem dull and to lie down,-indeed, they appeared unable to stand. Sometimes there ensued an attack of convulsions; these effects passed off in about an hour, and there remained exophthalmos, dilatation of the pupil, and widening of the palpebral fissure, and (as was thought) increased intraocular tension.

In three cases thyroid extract was injected as well as cocain, but its addition made no difference that could be detected. When the cocain injections were stopped the symptoms at once ceased: it seemed impossible to start a disease in any way resembling exophthalmic goitre by administration of cocain or thyroid extract, either separately or together.

In 7 of the monkeys, a few days before commencing the cocain injections, a long piece of the sympathetic nerve in the neck was excised. The effects of the excision were to produce contraction of the pupil (which came on as the effects of the anæesthetic passed off). 
and retraction of the eye; the effect of cocain subcutaneously on such a monkey is to greatly dilate the pupil on the normal side, and to cause proptosis there. On the operated side the pupil is somewhat dilated, but not so much; apparently no proptosis is produced, but it is not easy to be absolutely certain of this, as the opposite side is no longer normal for comparison; if there is any proptosis it certainly is not much, for the eye is not nearly so prominent as on the unoperated side. This effect of division of the sympathetic is very important, for it affords an indication for treatment in these cases of Graves's disease, in which the prominence of the eye is so great as to cause ulceration of the cornea. The usual treatment is to partially or wholly close the palpebral opening by suturing the eyelids together, but this is not always successful ; sometimes, notwithstanding this, and also strapping the lids together, the cornea sloughs, and the eye (or even both eyes) is lost. The effects of paralysis of the sympathetic in man are not serious-contraction of pupil and absence of perspiration on that side; the affection is generally only discovered accidentally.

The effects of cocain, then, it must be admitted, show the possibility of a poison being secreted by the thyroid which might cause symptoms like those of Graves's disease.

The real issue is whether the goitre of Graves's disease is primary, and by its secretion the cause of the other symptoms, or whether the disease is primarily of nervous origin.

In favour of the latter view it may be said that the relations of the disease are not so much thyroidal as neurotic.

The majority of those who have had an opportunity of judging appear to think that Graves's disease is not more common in goitrous districts than elsewhere. On the other hand, it has many nervous connections. Solbrig relates the case of a boy aged 8 (the son of a woman who suffered from the disease), who, after a disappointment at school, was seized with palpitation and profuse sweating; the next day the thyroid was large, the eyes prominent, and the pulse 180 . Two days later the symptoms gradually disappeared, and in 10 days he was well again. Putnam cites from Coggeshall an exactly parallel case. The patient was a young girl, and the symptoms followed immediately on great excitement attending a whipping, but subsided in a few days.

Again, certain experimental lesions of the central nervous system (of the restiform bodies) have been stated by Filehne and Bienfait to be capable of causing the symptoms of Graves's disease, namely, tachycardia, exophthalmos, and hyperæmia of the thyroid (but not a definite goitre). Further, Mendel found post-mortem, in a case of Graves's disease, atrophy of one restiform body.

The disease, too, has some relations with diabetes. Dr. Acland had recently under his care in St. Thomas's Hospital a patient suffering from diabetes, and passing between 4 and $5 \mathrm{oz}$. of sugar in the 
24 hours. Eighteen months previously the patient had been admitted with Graves's disease, suffering from a considerably enlarged thyroid and palpitation; on his second admission the thyroid was much smaller, though still enlarged, and the palpitation absent though the pulse was still quick.

An irritation of the sympathetic nerve, either applied to its origins in the central nervous system (brain or cord) or to its prevertebral ganglia, would readily enough account for both the cardiac and the ocular symptoms; as to the hypertrophy of the thyroid, it has been shown that stimulation of the sympathetic causes an increased secretion of the solid constituents of the saliva; the thyroid closely resembles the salivary glands, differing from them mainly in not draining through a duct, and it may be conjectured that prolonged stimulation through the sympathetic might cause the hypertrophic changes. The thyroid contains similar granules to those found in the secreting cells of the parotid gland (Plate XXX. Fig. 25).

Again, occasionally the eye symptoms are unilateral, and then the hypertrophy of the thyroid is generally greater on the same side as the affected eye. It was so in a case recorded by Maher, of Sydney.

The great improvement, if not recovery, in which Graves's disease in many cases terminates seems to negative any pronounced central lesion, and we need not therefore be surprised that none has been with certainty yet established.

Somewhat against the secretion theory is the fact that no poison has yet been found in the blood or spleen in experimental athyroidea. The blood from a dog dying of acute myxœdema, following thyroidectomy, was drawn and defibrinated, and injected into a vein of a normal $\operatorname{dog}$ : no effect-certainly no permanent effect-was produced. This experiment was tried five times. Also the albumoses was extracted from the spleens of dogs dead of athyroidea. Mr. White, pharmaceutist to St. Thomas's Hospital, kindly did this for me. The principle of the method depends on the facts that alcohol precipitates in the spleen the albumoses, the albumens, and the globuloses. At the end of about 3 months the last two are insoluble in water, while the albumoses are still thus soluble. They are dissolved, and the bulk is concentrated by evaporation at a low temperature and barometric pressure, and precipitated again by alcohol, and this is repeated several times in order to obtain a pure product: the albumoses thus obtained were injected subcutaneously into guinea-pigs with an entirely negative result. It would probably have been better if the injection had been intravenous.

The experiments related above were made at the Brown Institution, and the writer has much pleasure in expressing his thanks for the opportunities afforded him. 


\section{REFERENCES.}

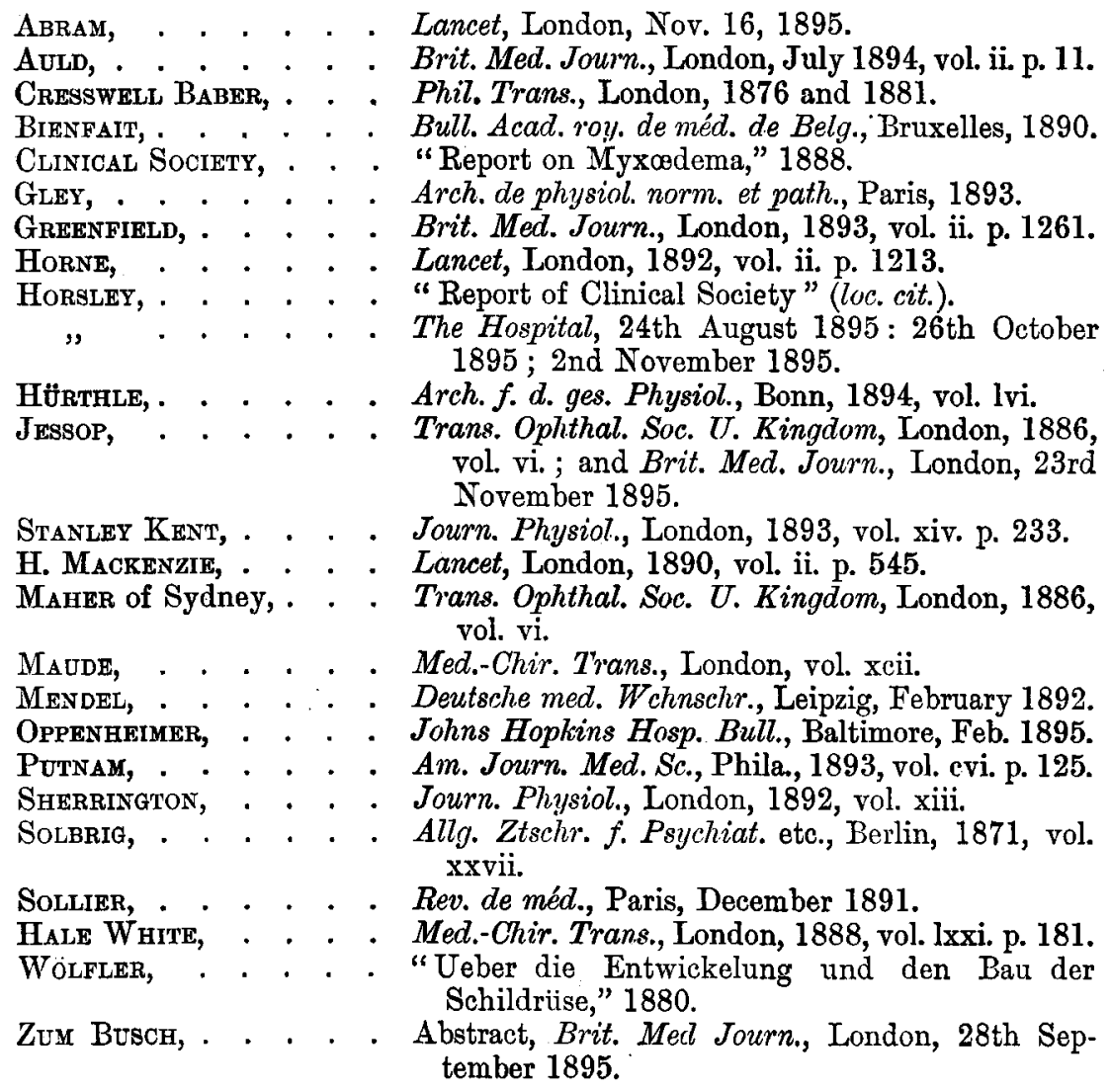

DESCRIPTION OF PLATES XXIV. TO XXXIV.

Plate XXIV.

FIGs. 1, 2, 3 and 4. Sections from the goitre in a case of Graves's disease.

A portion of the goitre was removed by operation, and from this the sections made. There will be noticed (1) the large amount of young secreting (thyroid) tissue between the vesicles ; (2) the hypertrophy of the secreting cells lining the vesicles; (3) the multiplication of these cells; in some vesicles they completely fill the cavity; (4) in Fig. 4 an inflamed artery and also a vein containing blood. $(\times 380$.

These and all the other specimens were obtained as fresh as possible, fixed in Foa's solution, and hardened in alcoholic solutions of gradnally increasing strength; they were embedded in paraffin. Various staining reagents were used, the most satisfactory being logwood and eosin, logwood and rubin, methylene-blue and rubin, and the Ehrlich-Biondi-Heidenhain stain. The drawings were made by Mr. Lapidge with Powell and Lealands, $\frac{1}{8}$ in. and in. $\frac{1}{12}$ apochromatics. 


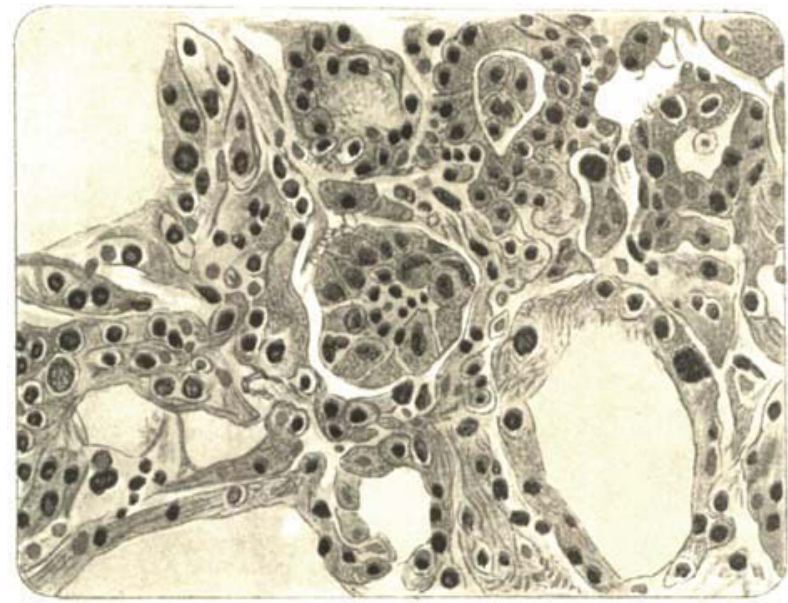

Fig. 2 .

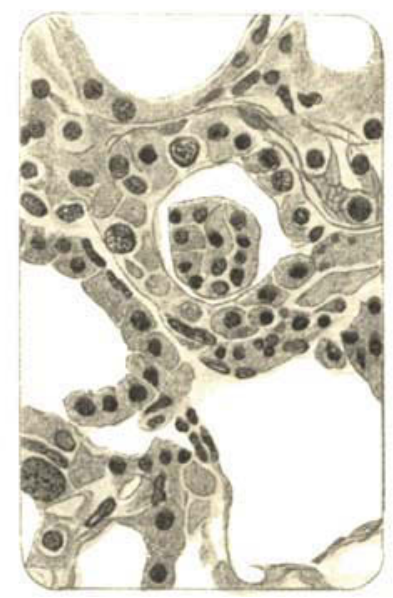

$\bar{F} \operatorname{si}$

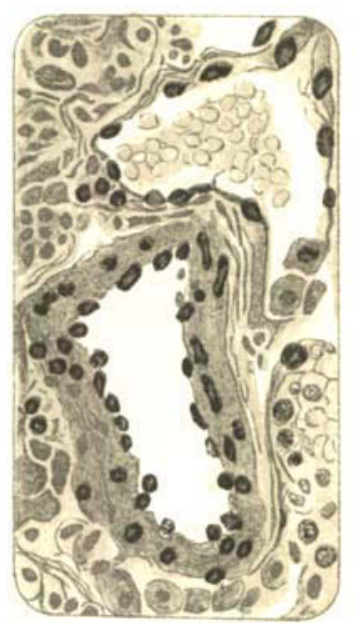

$F i 3$

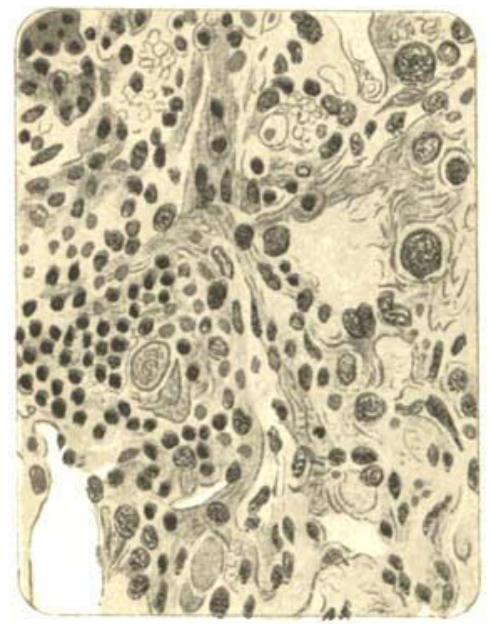

Fry 4 .

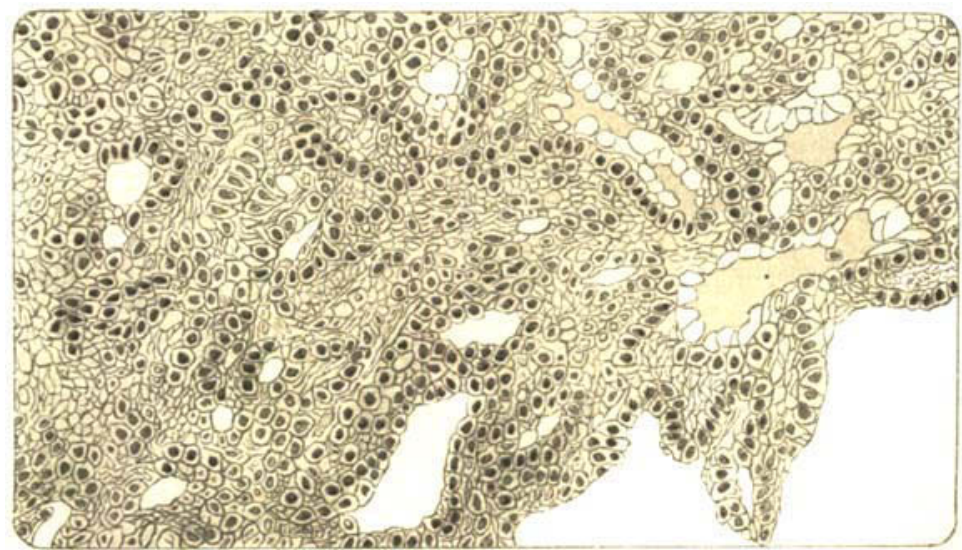




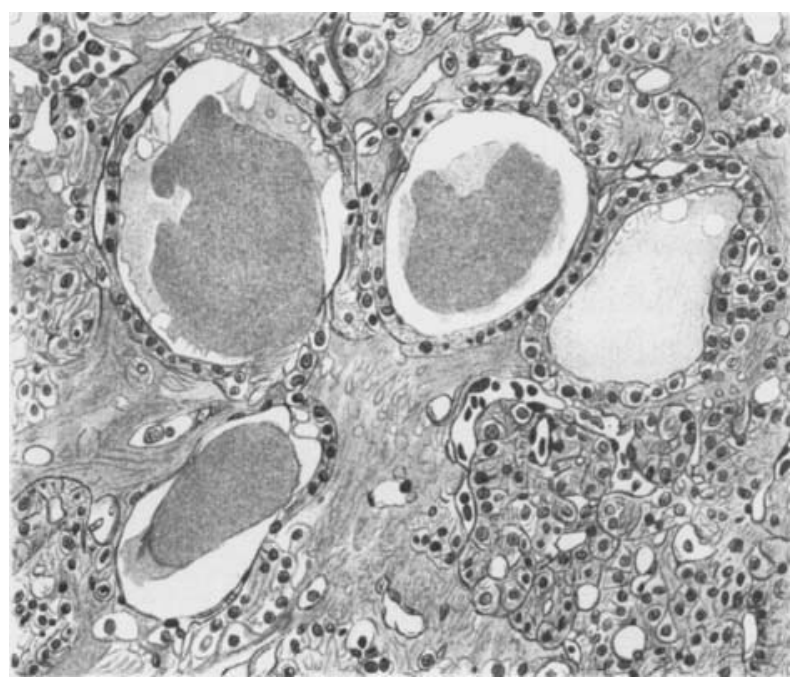

F.o 5

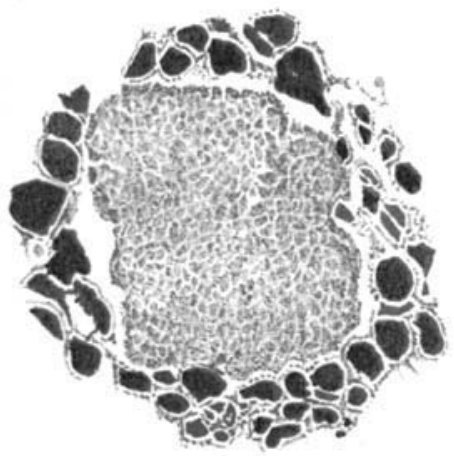

Fig. 7

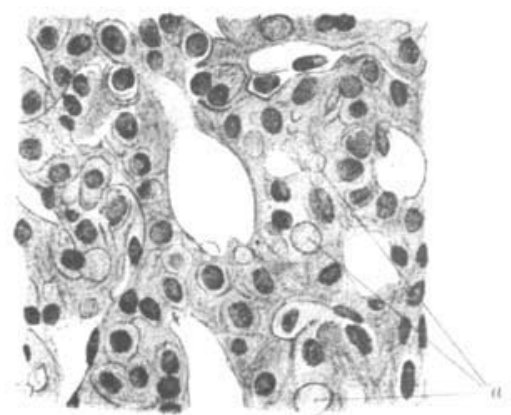

Fig 's

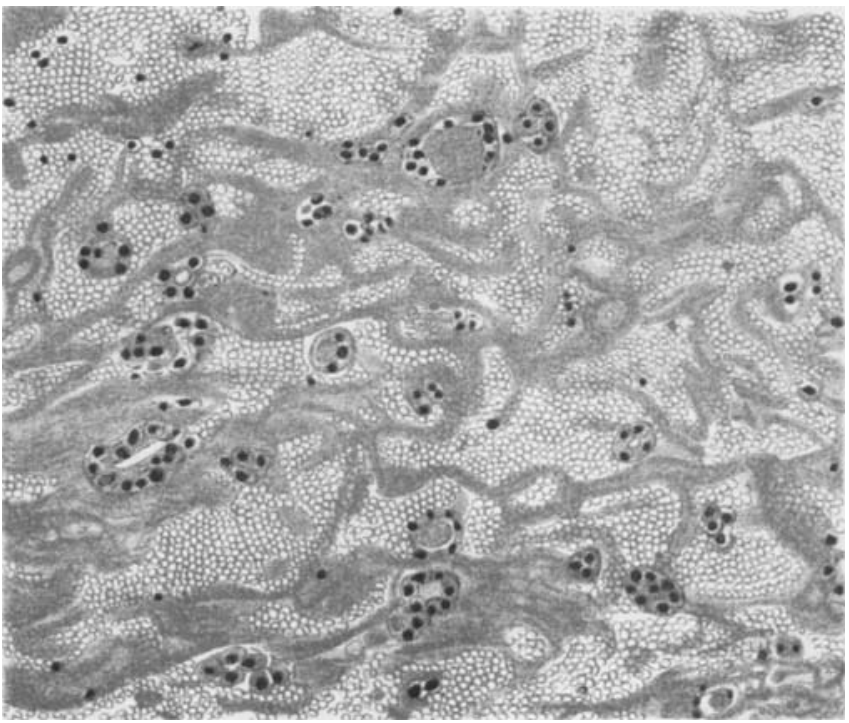



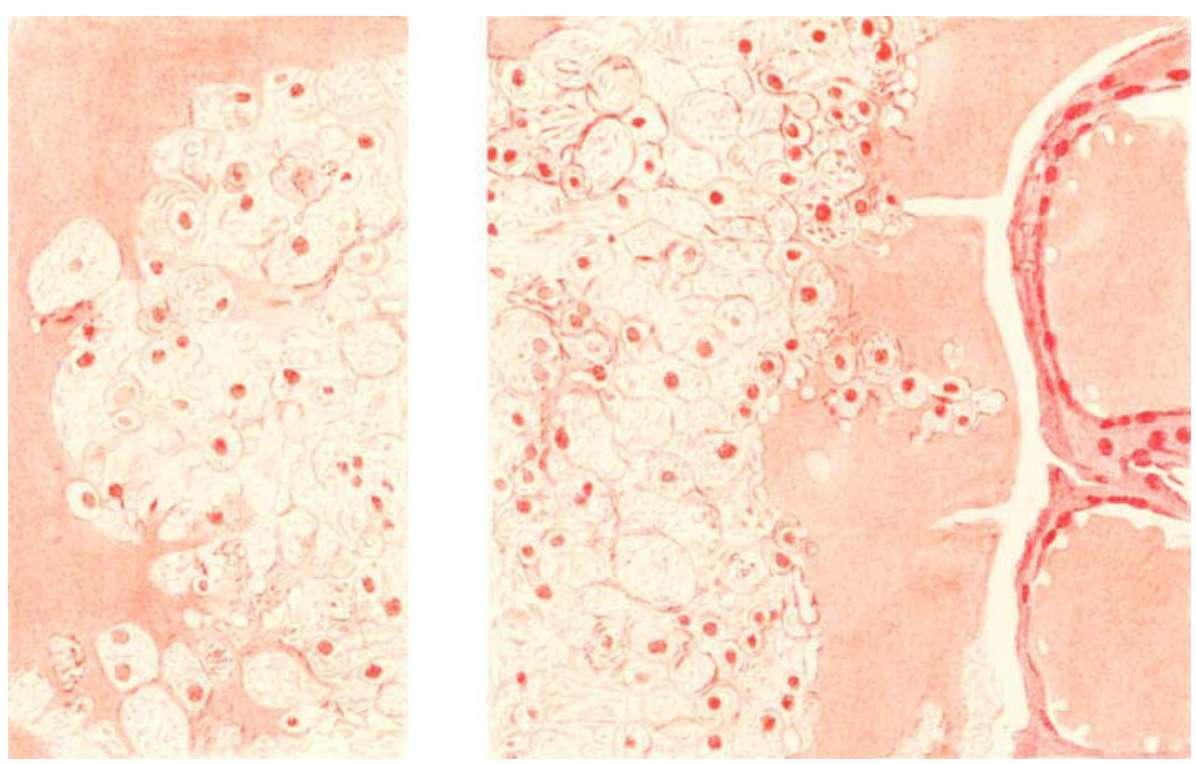

Fig. 10.
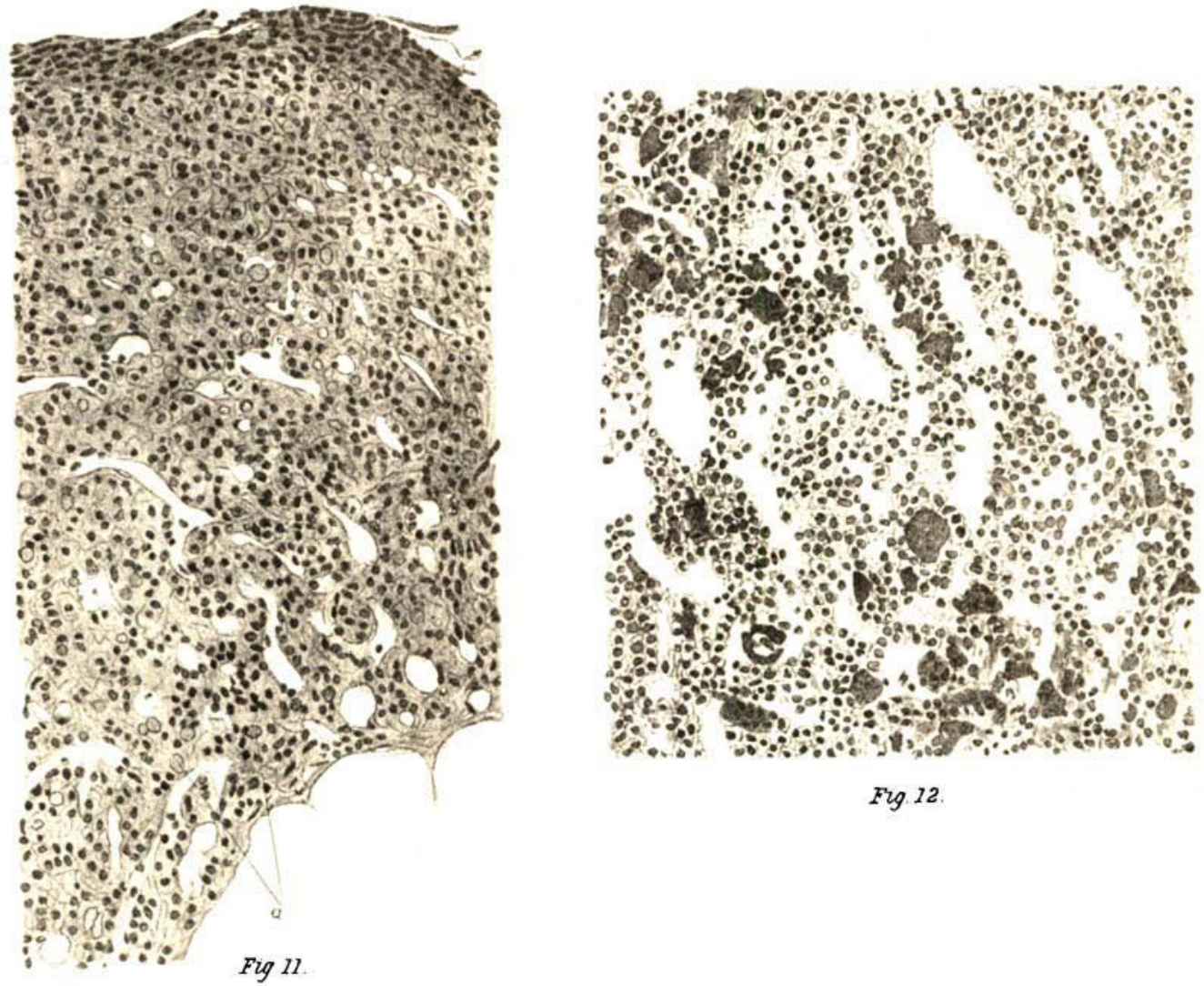

Fig. 12 


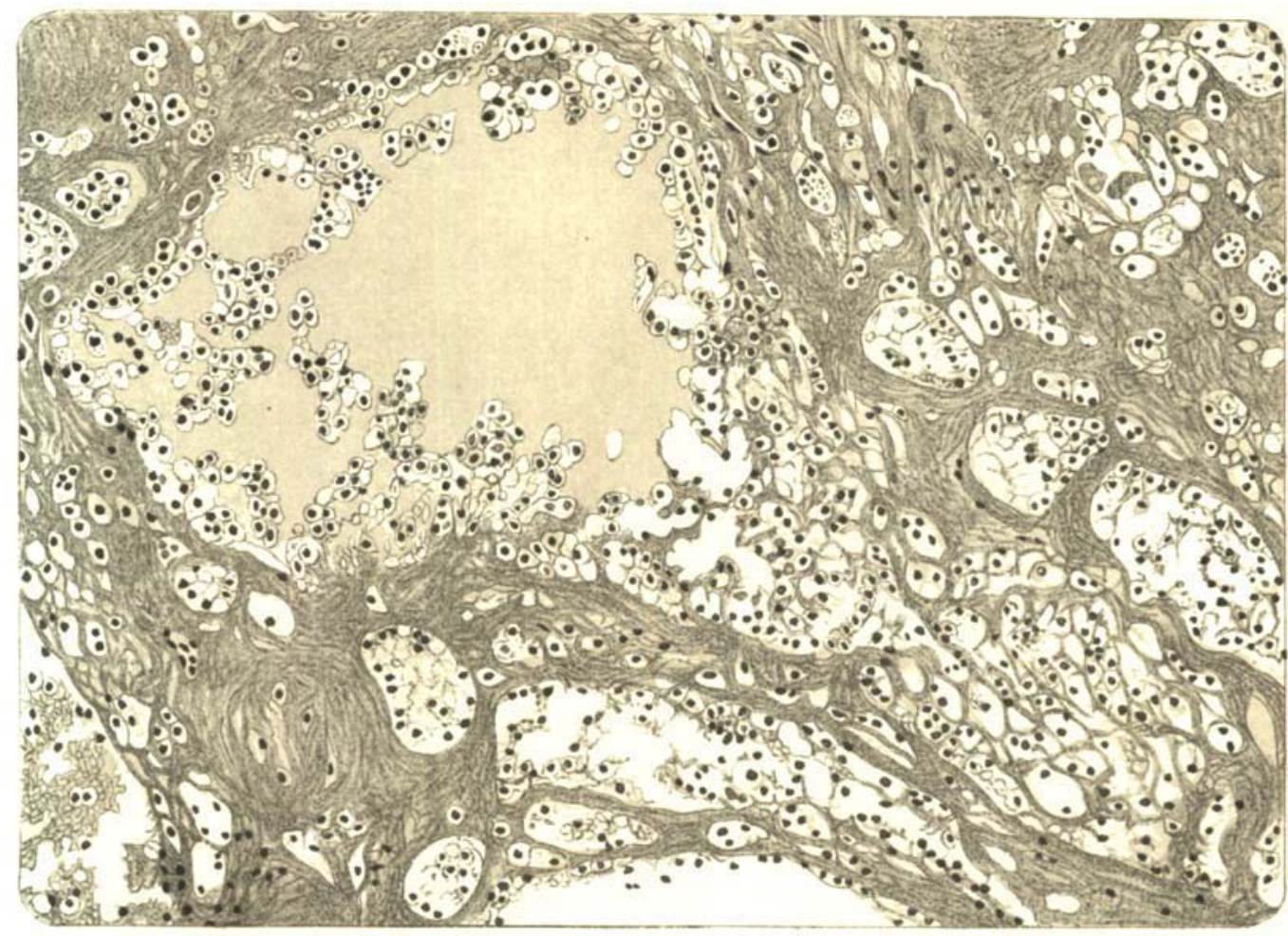

Fig. 13

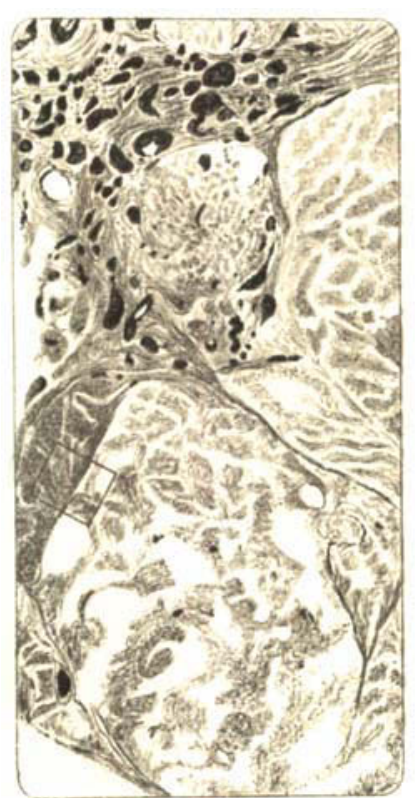

Fig. 24.

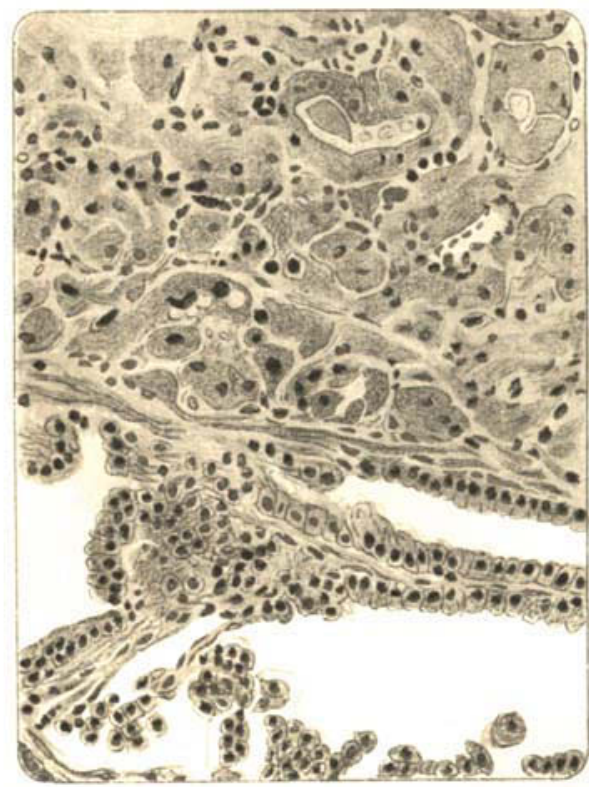

F.g. 25 . 


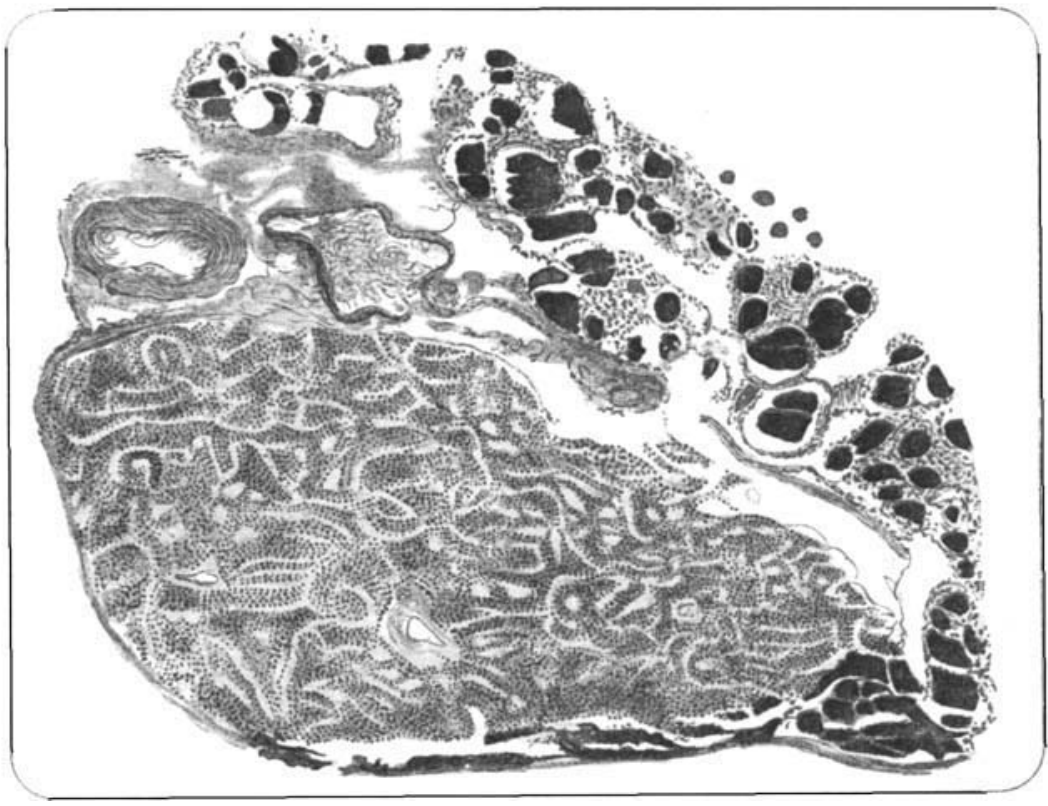

Fig. 76.

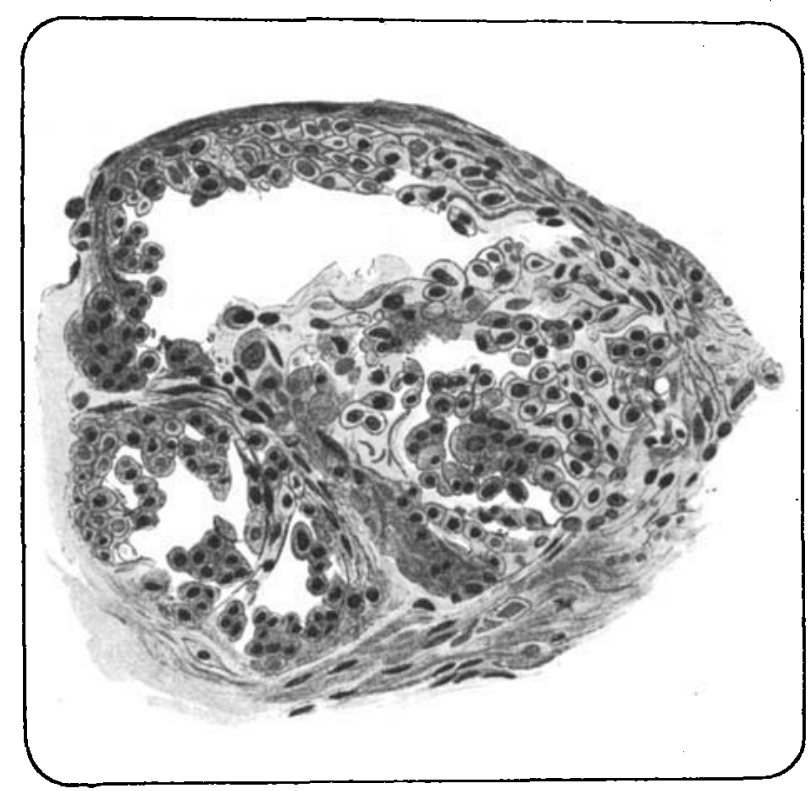

Fig 17

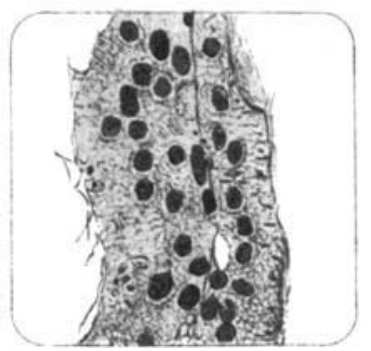

Fig 78

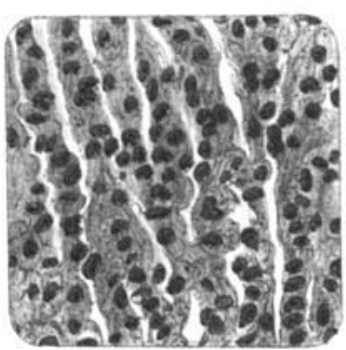

Fig. 19

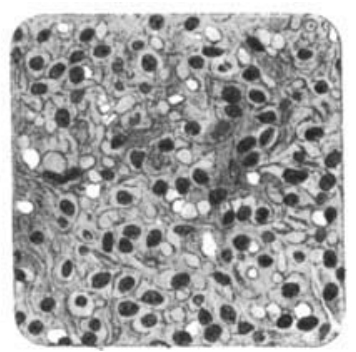

Fig 20 


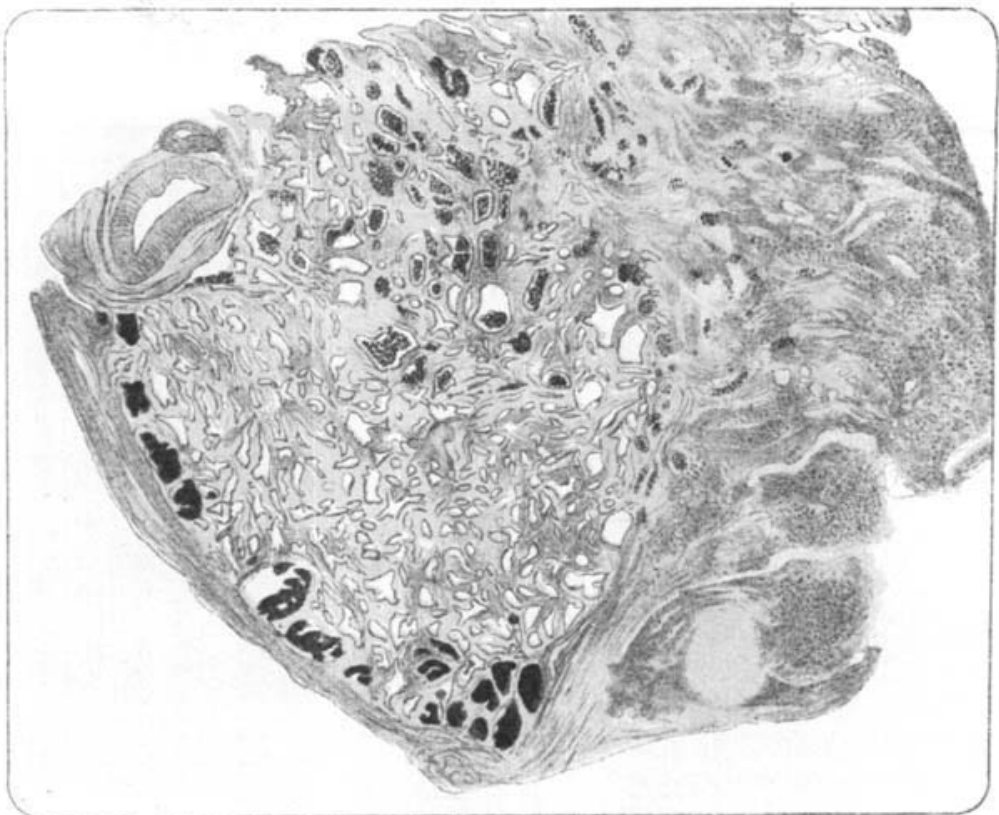

Fig 21.

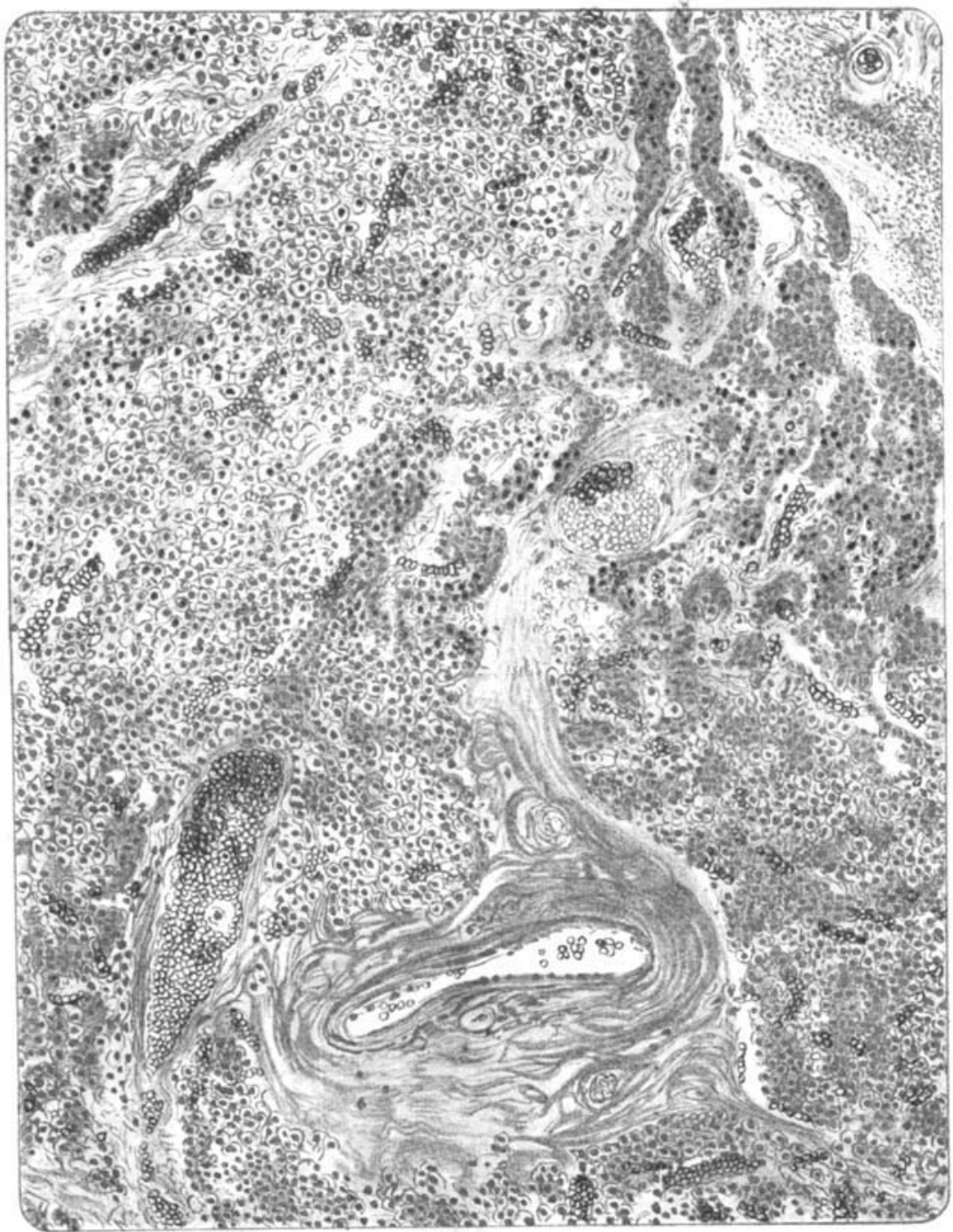




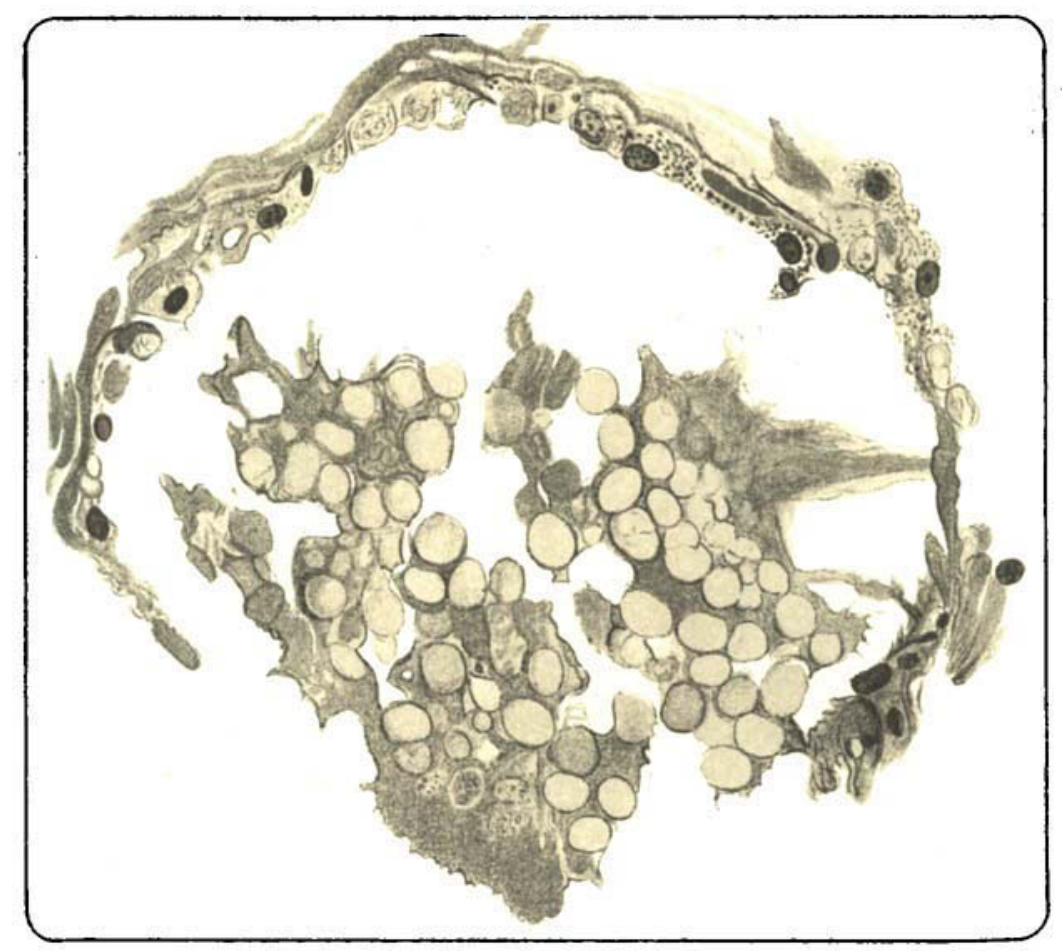

Fig. 24 .
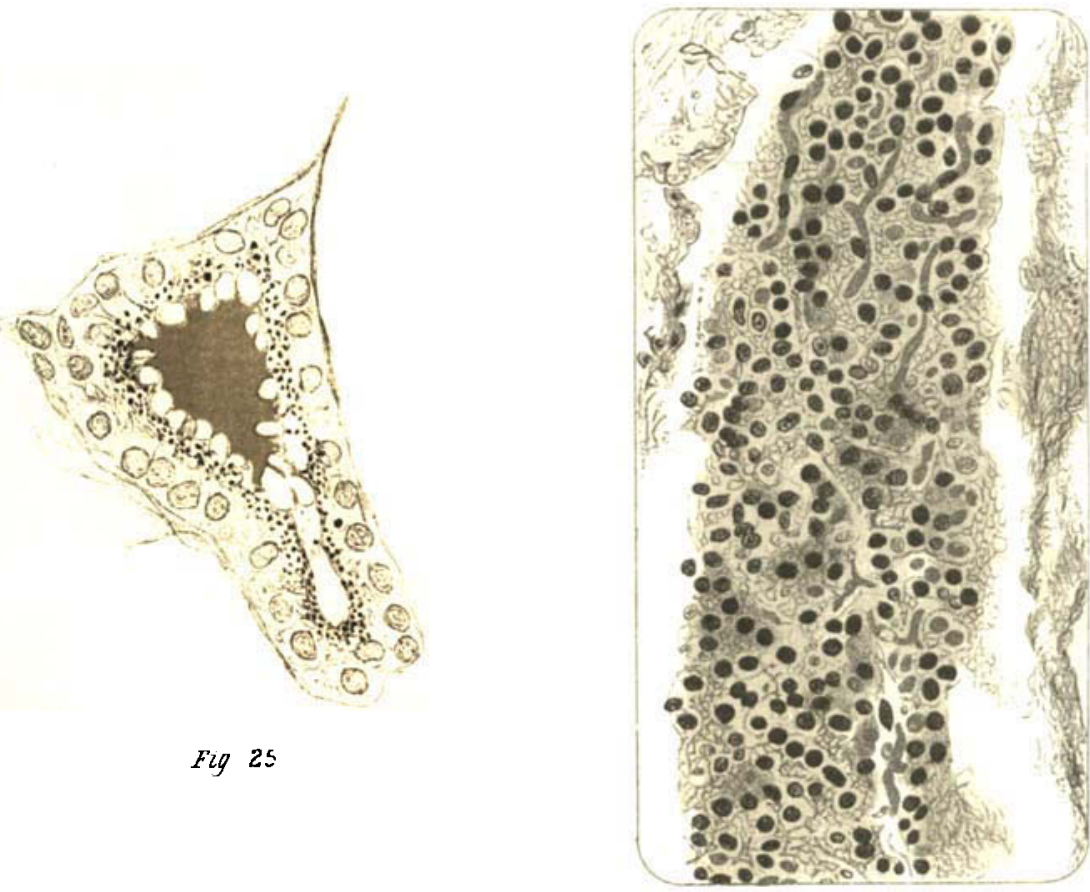

Fig. 26 


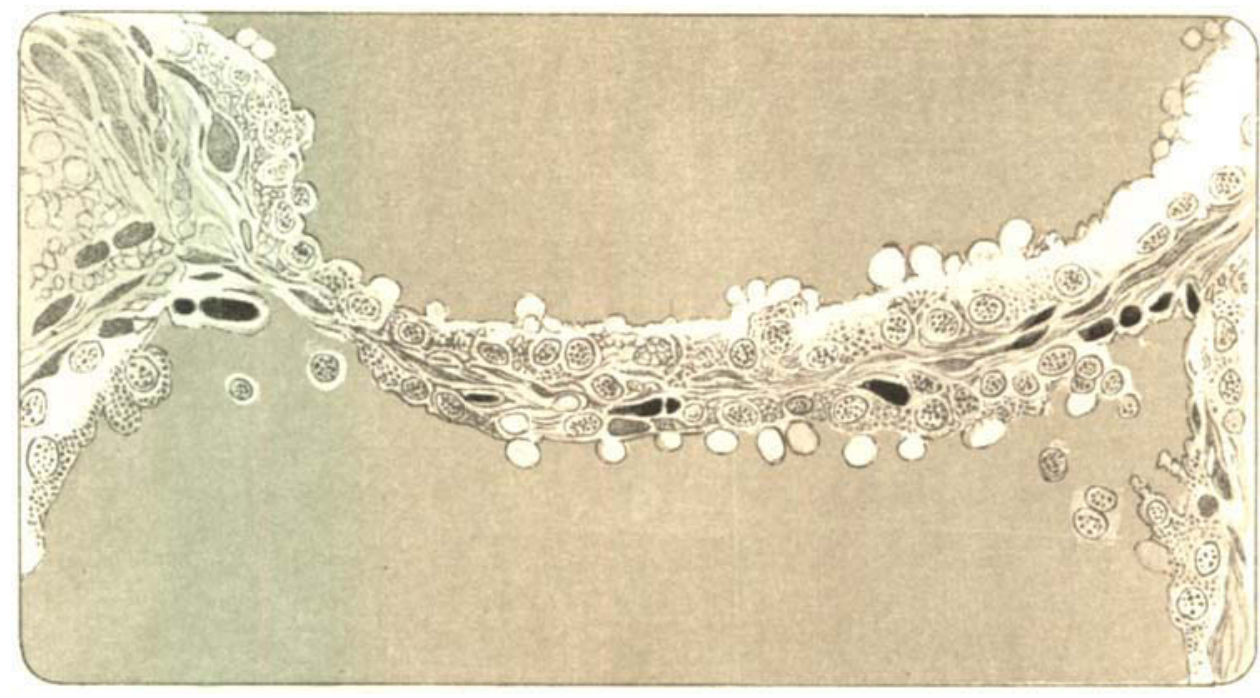

Fig. 27

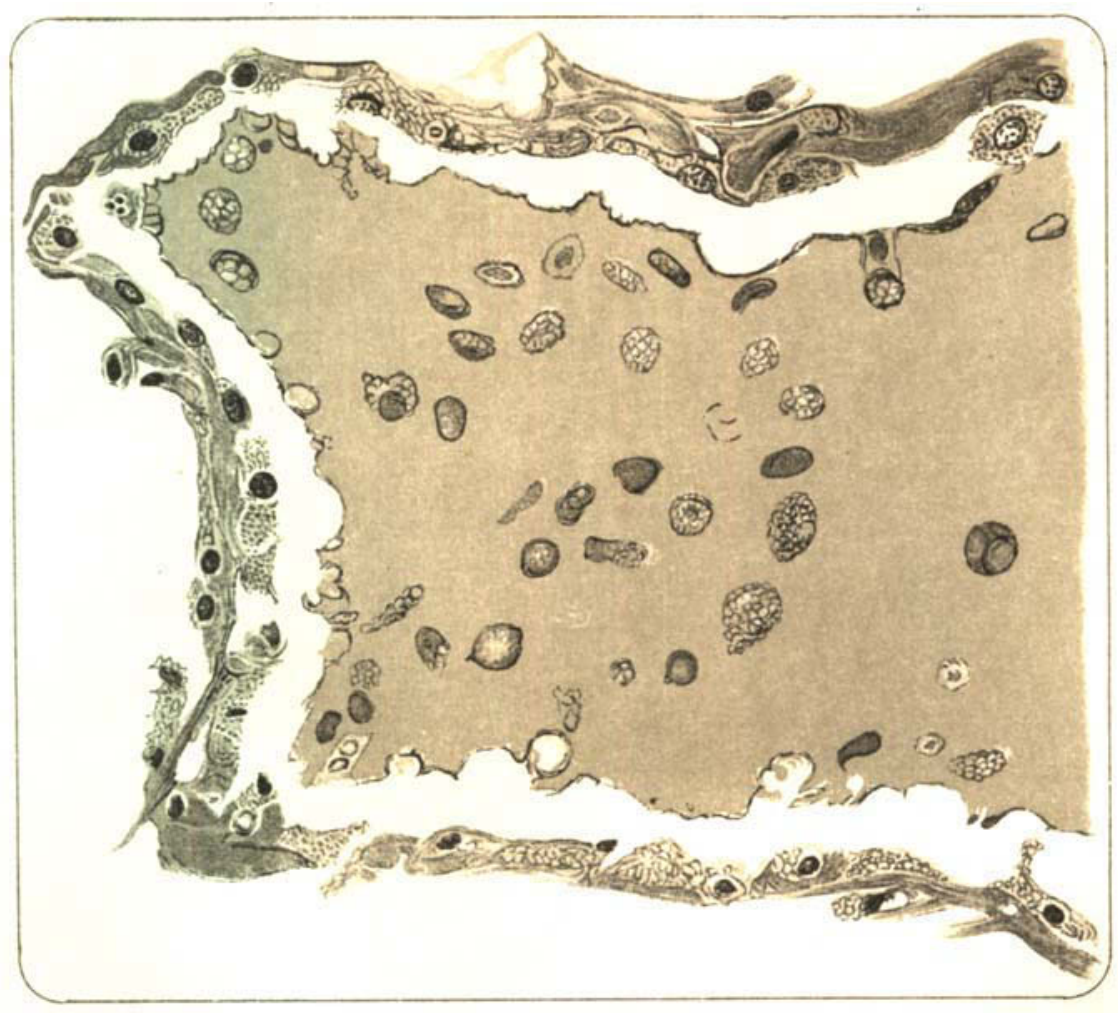




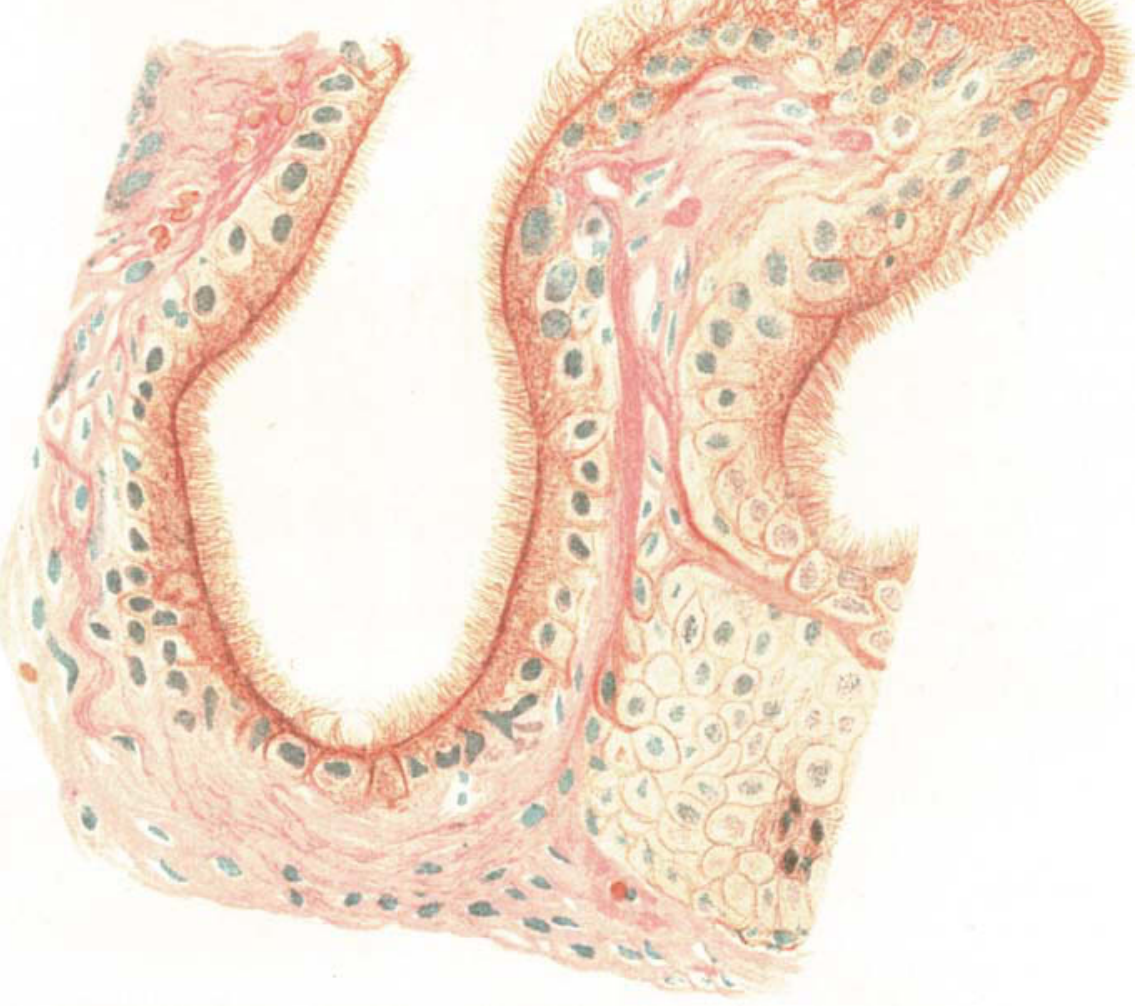

Fig. 29

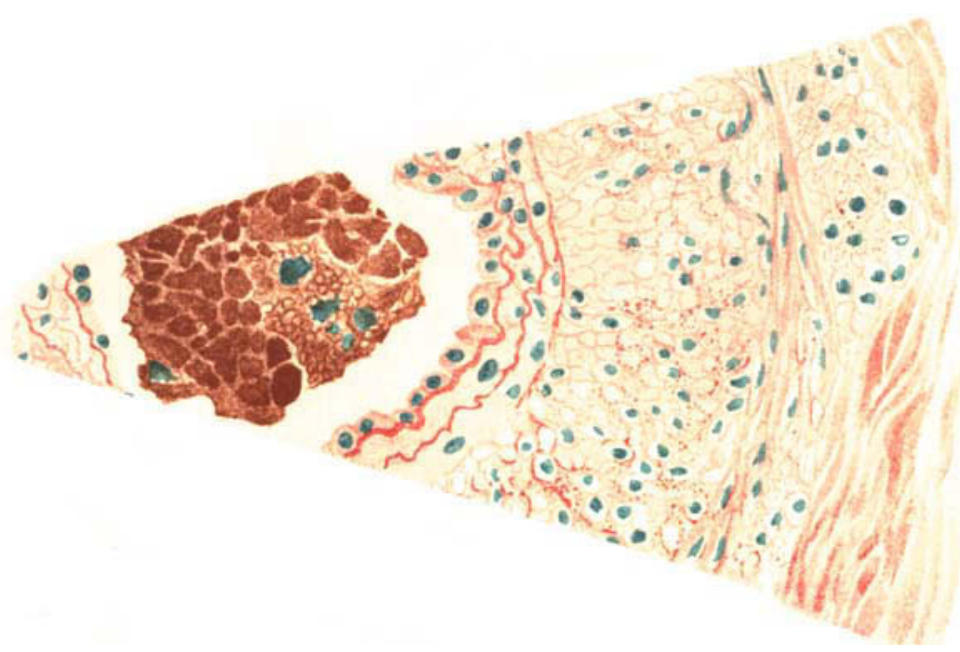

Fig. 30 
FrG. 5.-Section of goitre in a case of Graves's disease. The great amount of secreting cell tissues between the vesicles is to be noticed. $(\times 220$.

\section{Plate XXV.}

FIG. 6.-Section of goitre in a case of Graves's disease. There is a large amount of young thyroid tissue on the right, below; it will also be seen that the contents of the resicles have not stained uniformly; there is a central darker (normal) portion and a lighter external layer. ( $\times 220$.

FiG. 7.-Parathyroid of a monkey. The normal thyroid tissue completely surrounds it. It resembles that of the $\mathrm{dog}$, and is devoid of vesicles and of colloid secretion. $(\times 50$.

Fig. 8.-Represents the thyroid of a sheep. It is a portion of Fig. 11 more highly magnified. The lightly shaded small bodies with their outlines are drops of secretion which have not stained darkly as the colloid in thyroid vesicles does. $(\times 500$.

Fig. 9.-From an adenomatous goitre. The structure resembles erectile tissue. The spaces containing blood appear to communicate freely. $(\times 200$.

\section{Plate XXVI.}

Fic. 10.-From the goitre in a case of Graves's disease. The invasion of the colloid substance by large resicular cells staining with eosin; these cells are the descendants of the secreting cells lining the vesicle; on the left is seen a cell with two nuclei, presumably about to divide. ( $\times 380$.

FIG. 11.-Parathyroid of sheep. The smaller and shaded spaces consisted of drops of secretion, but it does not stain in the same way as the colloid in the resicles of thyroid tissue proper; the former stains palely, the latter darkly. Fig. 8 shows a portion of this section more highly magnified. $(\times 220$.

Fig. 12.-From a goitre occurring in a boy. A portion of the tumour was removed by operation on account of pressure symptoms. The structure is mainly cellular ; the colloid is recognised by the dark colour it has stained; it is not contained in well-defined vesicles. $(\times 250$. $)$

\section{Plate XXVII.}

Fig. 13.-From an adenomatous goitre. It will be seen that in the large vesicle occupying the field that the epithelial secreting cells have multiplied and invaded the colloid ; to the right, and below, the colloid has wholly disappeared, and here it is difficult to determine the exact limits of the vesicle. ( $\times 220$.)

FIG. 14.-From a fatal case of Graves's disease. Above, and to the left, the colloid is recognised by its dark staining. Above, and to the right, the tissure is papillomatous in character; the portion marked with a square is shown more highly magnified in Fig. 15. ( $\times 25$.)

FIG. 15. -The part marked in Fig. 14 more highly magnified. ( $\times 225$.

\section{Plate XXVIII.}

Fig. 16. - The parathyroid of a dog. Above, and to the right, thyroid proper tissue is seen, with the colloid darkly stained : it will be noticed that in the parathyroid there are no vesicles and no colloid; that is to say, no secretion that stains in the same way that the colloid does. $(\times 50$.

Frg, 17.-Section of the thyroid of a cretin. It was obtained from the body of a girl aged 10 years, who was the subject of cretinism. The thyroid did not appear atrophied. The sections show but little colloid in the resicles, and there is a considerable multiplication of the secreting cells lining them.

34-JL. OF PATH.-VOL. III. 
Possibly there is some antagonism between the multiplication of the secreting cells and the performance of their function of secreting. I am indebted to Mr. Bidwell for obtaining this specimen. $(\times 250$.

FIG. 18. - The whole of one lobe, including the parathyroid and the greater part of the other lobe, excluding the parathyroid of the thyroid of a dog, were excised. No symptoms followed, and at the end of 9 days the dog was killed. The figure represents, highly magnified, the lining (secreting) membranes of two adjacent vesicles baok to back. It will be noticed that the membranes are much hypertrophied, and that this is obtained rather by the enlargement of the cells than by their multiplication (contrast with Fig. 17). Fig. 21 is from the same specimen but less magnified. $(\times 500$.

FIG, 19.-Section of accessory thyroid of rabbit. 102 days previous to the rabbit being killed and this specimen obtained, the whole of the thyroid proper of the rabbit had been removed, leaving only the two parathyroids. These after death were found not to be much, if at all, hypertrophied, nor was their microscopic appearance much altered. No vesicles and no colloid were seen, $(\times 380$,

FIG. 20.-Section of normal accessory thyroid of rabbit. It contains no vesicles and no colloid. The clear spaces are probably due to secretion, but this does not stain in the same way the colloid in the thyroid proper of a rabbit does. $(\times 380$,

\section{Plate XXIX.}

Fıa. 21.-From the same specimen as Fig. 18, of which see description. Section of small portion of thyroid left after the removal of the greater portion 9 days previously. The thickening of the secreting lining of the vesicles and the absence of colloid from many of them is noticeable. $(x 25$.

Figs. 22 and 23. - Section of a small nodule on the surface of, or in the vicinity of, the normal human thyroid. (The patient, a young woman, had died of phthisis.) It will be observed that there are no vesieles and no colloid, and that the structure consists mainly of columns of cells, thus resembling the structure of the embryonic thyroid, and also of the parathyroid as seen in various mammals. $(\times 220$.)

\section{Plute: XXX.}

FIG. 24. - A vesicle highly magnified from the normal thyroid of a man aged 65 years. The formation of separate globular masses in the colloid is to be noted. ( $\times$ 380.)

Fia. 25. - A single vesicle from a case of adenoma of thyroid. It is drawn to show the close resemblance between the thyroid and salivary glands. It should be compared with the drawings of the latter, which are to be found in most text-books of Physiology. The black granules are similar in appearance to those found in the salivary gland. $(\times 500$.

Fra. 26.-Normal accessory thyroid of rabbit: the specimen had been injected. Notice absence of vesicles and of colloid. $(\times 380$.

\section{Plate XXXI.}

Fra. 27.-From the normal thyroid of a girl, aged 14 years. It shows the secreting lining membranes of two adjacent vesicles back to back. The dark substance above and below is the colloid in the vesicles; the two layers (one in each vesicle) of secreting cells are seen; and also some circular spaces in the colloid; the nature of these "vacuoles" has given rise to some difference of opinion; many consider them as simply due to shrinkage, and this view is strongly supported by the fact that they do not occur in specimens fixed with osmic 


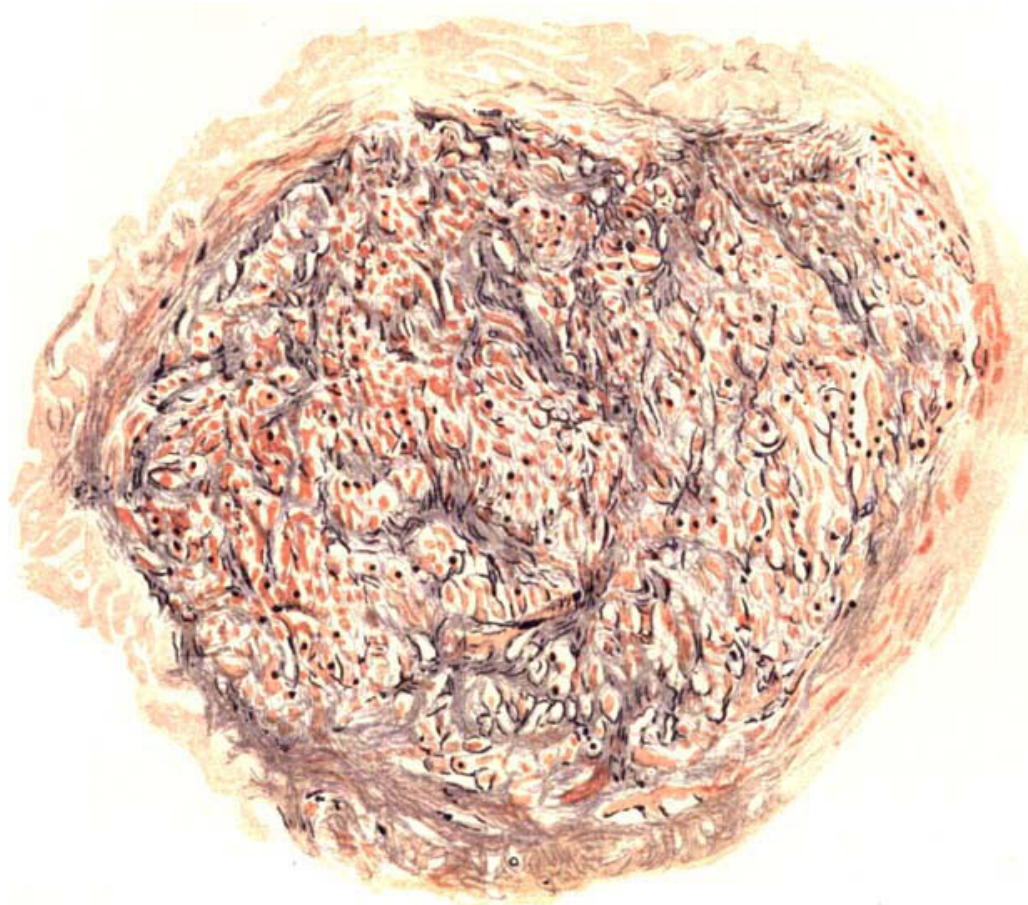

Exg. 32

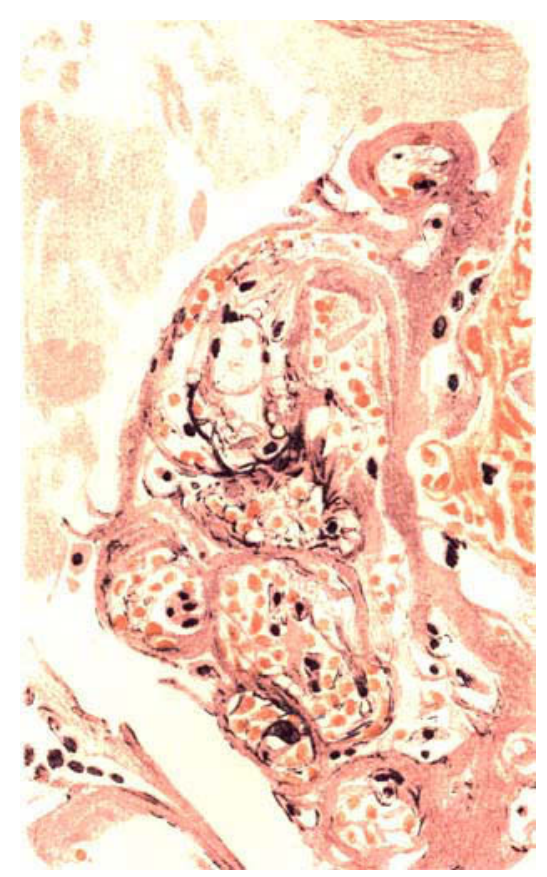

Fig. 32 


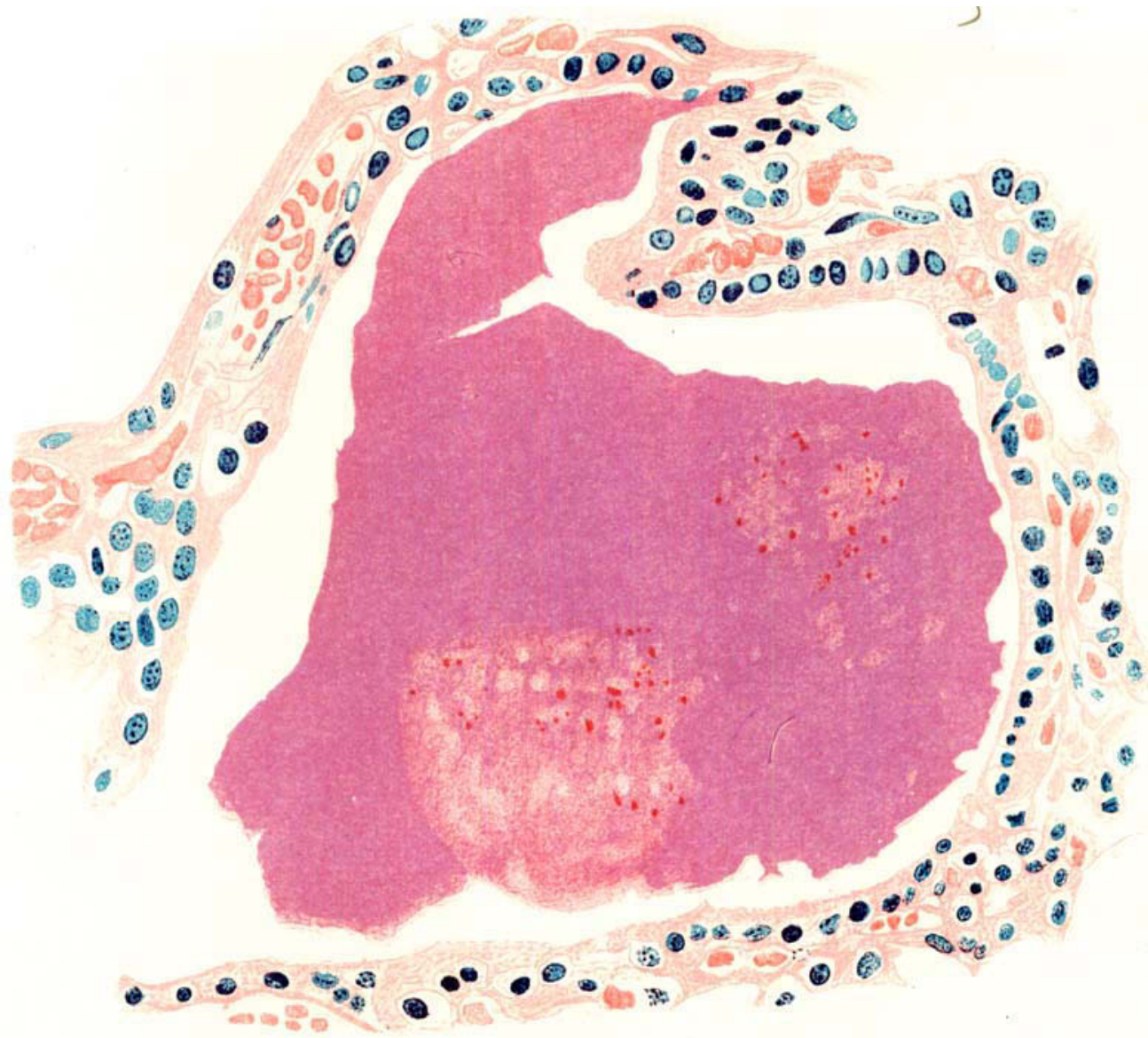

Fig. 33.

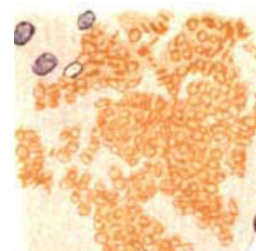

8. A 5 .

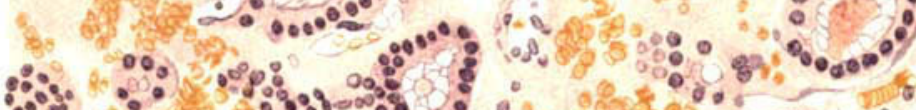

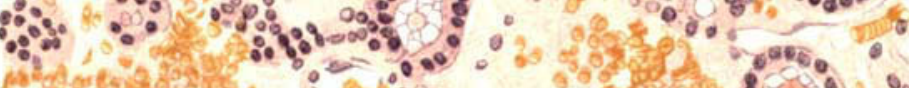

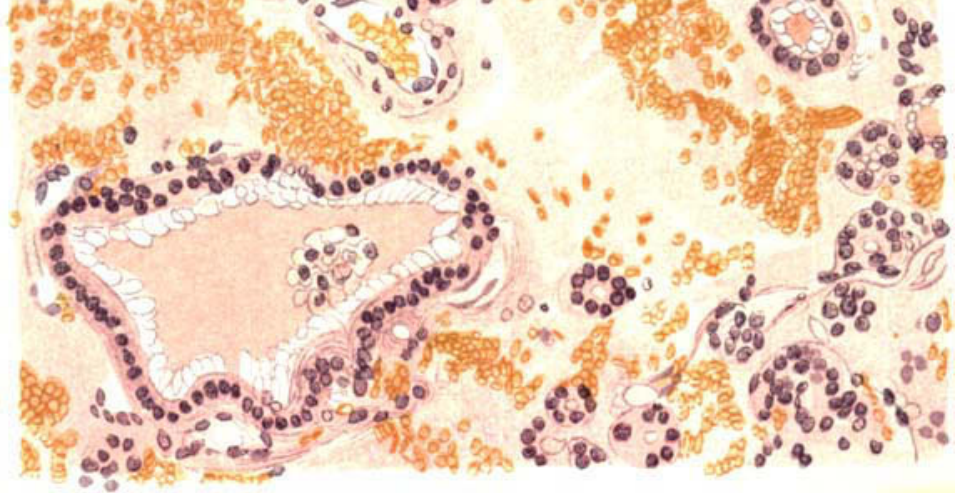

Fig. 34 
acid. Creswell Baber attributes them to the action of alcohol in drawing out from the secreting cells drops of watery fluid which cause the appearance of the vacuoles. Their uniformly small size, however, and the fact that they occur in the vicinity of large (active) secreting cells, and are absent from over flat (inactive) cells, suggests that they are due to drops of secretion which have been quite recently poured out and have not yet become mixed with the colloid proper. See Hürthle's "Kenntniss des Secretionsoorgangs in der Schildriise," in Pflüger's Archiv fiir Physiologie, bd. vi. (1894), plate i. fig. 5. Similar vacuoles occur in blood vessels where clot is undergoing absorption. See Ballance and Edmunds' "Ligation in Continuity," plates vii. and viii. $(\times 380$.

FIG. 28.-Section from a vesicle from the normal thyroid of a man aged 65. Cells descended from the secreting cells on the wall are scattered through the colloid. $(\times 380$. $)$

\section{Piate XXXII.}

FiG. 29.-From the parathyroid of a dog. The presence of ciliated epithelium is abnormal, and is interesting in connection with the development of the thyroid gland. Ehrlich-Biondi staining. $(\times 380$.)

FIG. 30.-Segment of a tranverse section of an hypertrophied arteriole in a case of Graves's disease. To the right is seen the lumen of the vessel occupied with a clot which is undergoing absorption. The surface of the artery is to the left. The hypertrophy is greatest in the imtina. Ehrlich-Biondi staining. $(\times 380$.

\section{Piate XXXIII.}

Fig. 31.-A small globular knot of coarse fibres containing in their meshes cells probably of epithelial origin. The specimen was obtained from a somewhat fibrous goitre that was undergoing degeneration. Logwood and eosin staining. $(\times 220$.

Fic. 32.-A degenerating goitre. The intervesicular tissue and the walls of the vesicles have undergone a hyaloid change. Logwood and eosin staining. ( $\times 380$.

\section{Plate XXXIV.}

Fra. 33.-From the normal thyroid of a child aged 4 years. The secreting cells lining the vesicle are well seen. Their nuclei are stained with methylene-blue : the blood cells in the capillaries are stained bright red with rubin. In the colloid are seen numerous bright red bodies, which are probably red blood corpuscles breaking down. ( $\times 380$.)

FIG. 34.-From a case of goitre. A portion of the goitre was removed by operation. Specimen stained with logwood and rubin. A large part of the tiseue between the vesicles has undergone a degeneration which is sometimes spoken of as calloid; it stains quite differently to the colloid in the vesicles, and should perhaps be spoken of as a hyaloid change. Numerous blood corpuscles are scattered throughout the intervesicular tissue. $(\times 225$. $)$ 